\title{
Julgamentos a serviço da História
}

\author{
Judgments service History
}

\author{
Aline Michelini Menoncello \\ aline_menoncello@hotmail.com \\ Mestra em História (Bolsista Capes) \\ Universidade Estadual Paulista Júlio de Mesquita Filho \\ Av. Dom Antônio, 2100 - Parque Universitário \\ 19806-900 - Assis - SP \\ Brasil
}

\section{Resumo}

Ao percorrer as atas da Revista Instituto Histórico e Geográfico Brasileiro (RIHGB) entre 1901 e 1921, analisei a participação de Pedro Augusto Carneiro Lessa (1859-1921), o ministro do Supremo Tribunal Federal. E deste modo interroguei-me: quem trabalha pela História no Instituto Histórico é o juiz Pedro Lessa ou o historiador Pedro Lessa? Tal pergunta será respondida a partir da problematização da categoria "autor" oferecida pelo filósofo francês Michel Foucault e pela análise dos textos assinados por Pedro Lessa: os pareceres emitidos para a Comissão de História, o estudo para o centenário de nascimento de Francisco Adolfo deVarnhagen e o Laudo Definitivo para decidir a data comemorativa da Confederação do Equador.

\section{Palavras-chave}

Escrita da História; Discurso; História da Historiografia.

\section{Abstract}

By going through the records of the Brazilian Historical and Geographical Institute Magazine (RIHGB) between 1901 and 1921, I investigated the participation of Pedro Augusto Carneiro Lessa (1859-1921), Minister of the Supreme Court. Thus I asked myself: who works for History in the History Institute, the judge Pedro Lessa or the historian Pedro Lessa? This question will be answered from the questioning of the category "author" offered by the French philosopher Michel Foucault and analysis of the texts signed by Pedro Lessa: the evaluation in History Commission, the study for the centenary of the birth of Francisco Adolfo de Varnhagen and the Final Report to decide the commemorative date of the Confederation of the Equator.

\section{Keywords}

History writing; Discourse; History of Historiography.

Recebido em: 21/10/2016

Aprovado em: 5/12/2016 
Desde 1907 até 1921, nosso exímio colega prestou a esta laboriosa companhia os mais relevantes serviços, como membro da Comissão de História, relator de numerosos e brilhantes pareceres [...].

Entre seus lúcidos trabalhos, seja-me licito salientar [...] as duas magistrais conferencias, que aqui aplaudimos a 17 de fevereiro de 1916 e 2 de julho de 1918.

$[\ldots]$

Estas duas memórias bastariam para lembrar com muita honra o nome de Pedro Lessa, tal a agudeza de sua crítica, a abundância de sua argumentação, a segurança de seu juízo. Historiador e juiz, não se poderiam aliar mais admiravelmente os altos predicados daquele espírito superior (Elogio Fúnebre de Ramiz Galvão 1921, p. 884).

Pedro Augusto Carneiro Lessa (1859-1921), o famoso ministro do Supremo Tribunal Federal (STF), pulicou o livro É a história uma ciência? (1900) ${ }^{1}$. Essa obra é a mais conhecida pelos historiadores, pois foi classificada como histórica pelos sócios do Instituto Histórico e Geográfico Brasileiro (IHGB) em 1901, quatro décadas mais tarde, os editores do Suplemento Autores e Livros atualizaram o lugardela, como obra histórica (GOMES 1996). E recentemente o mesmo texto foi revisitado, interrogado e bem investigado para compreender a relação entre História e Ciências Sociais na Primeira República por Hugo Hruby (2007), Angela de Castro Gomes (2009; 2010; 2015), Piero Detoni (2013) e Bárbara Winther da Silva (2015).

É a história uma ciência? foi lida, avaliada e aprovada pelas Comissão de História e Comissão de Admissão de Sócios do IHGB, e assim, Pedro Lessa foi agraciado com uma vaga de sócio correspondente em 1901. Porém, só pôde tomar o assento após realizar o discurso de posse que aconteceu no dia 10 de junho de 1907. Até aquela ocasião, Pedro Lessa era professor da Faculdade de Direito de São Paulo e, alguns dias mais tarde, foi convidado pelo Presidente Afonso Pena a substituir a vaga de Lúcio de Mendonça no STF. Residir na antiga Capital do Brasil, ou seja, na cidade do Rio de Janeiro, possibilitou a Pedro Lessa não apenas exercer a sua função de juiz, mas também uma maior participação nas atividades no IHGB. Desse modo, ele deixou a categoria de sócio correspondente e passou a atuar como sócio efetivo do Instituto.

O IHGB era uma instituição antiga, foi fundado em 1838 e contava com prestígio e auxílios financeiros do Imperador D. Pedro II desde 1841. A queda da monarquia em 1889 e o desprestígio dos marechais que assumiram a presidência da República brasileira levaram o Instituto a quase encerrar suas atividades. Isto só não aconteceu devido à criação da categoria de sócios beneméritos. Os beneméritos eram homens que poderiam fornecer donativos sem precisar demonstrar a "suficiência literária". Esta estratégia impediu o fechamento das portas do IHGB. Pedro Lessa foi contemporâneo dos sócios Ramiz Galvão, Conde de Afonso Celso e Max Fleiüss. Essas três personalidades atuaram na

\footnotetext{
${ }^{1}$ A polêmica e conhecida História da civilização na Inglaterra, de Henry Thomas Buckle (1822-1862), foi traduzida para a língua portuguesa em 1900; Pedro Lessa escreveu a introdução dessa edição. No mesmo ano, Lessa republicou esse texto, em formato de livro, com o título É a história uma ciência?, e, em 1906, o referido texto ganhou espaço na revista do Instituto Histórico e Geográfico Brasileiro (IHGB) com o título Reflexão sobre o conceito da história.
} 
administração do Instituto durante as décadas de 1910 e 1920, tiraram, mesmo que lentamente, a instituição do isolamento político. Nesse novo cenário e, sobretudo, durante o governo de Getúlio Vargas (1930-1945), o IHGB voltava a desfrutar dos prestígios intelectuais e também dos auxílios financeiros, que subsidiavam as pesquisas, participações em eventos no exterior e os congressos de História (GUIMARÃES 2007).

Pedro Lessa, apesar de não frequentar o Instituto com tanta assiduidade, foi vice-presidente da instituição, elevado em 1912 à categoria de sócio honorário, ${ }^{2}$ participou de várias comissões e apresentou três estudos. No final de cada ano realizava-se no IHGB a Assembleia Geral; nessa reunião os sócios candidatavamse aos cargos de presidência, de vice-presidência, de primeiro e de segundo secretários, de orador e de tesoureiro, assim como se candidatavam a membros das comissões permanentes - de Fundos e Orçamento, de Estatuto, de História, de Geografia, de Etnografia, de Arqueologia e de Admissão de Sócios - para o trabalho do ano seguinte. Pedro Lessa elegeu-se primeiro vice-presidente em 1909; concorreu ao cargo de orador em 1910 e 1911, mas perdeu as duas vezes para o Conde de Afonso Celso; em 1915, voltou a concorrer ao cargo de primeiro vice-presidente, entretanto perdeu para Manoel Cicero Peregrino da Silva; em 1918 e 1919, por fim, foi eleito segundo vice-presidente. Além dessas funções importantes, Lessa também integrou como membro a Comissão de História entre 1907 e $1920 .^{3}$

A Comissão de História constituía-se de modo permanente por cinco 240 membros eleitos em Assembleia Geral, responsáveis por analisar as obras consideradas históricas de um candidato a sócio correspondente ou efetivo. A comissão procedia da seguinte forma: primeiramente, o secretário comunicava, em sessão ordinária, a indicação de um candidato e informava a obra com a qual pleiteava tal vaga. Em seguida, a obra do candidato era encaminhada para a comissãocom o indicativo do relator. Sem prazo predeterminado, o relator avaliava a obra e escrevia o parecer. Com o parecer em mãos, os membros da comissão reuniam-se para debatê-lo e para aceitá-lo integralmente ou para apresentar ressalvas. Então, em outra sessão ordinária, o parecer era encaminhado para o presidente do Instituto e lido pelo secretário para todos os sócios e, somente se fosse favorável, encaminhava-se o parecer para a Comissão de Admissão de Sócios. Durante esse tempo, o então juiz Pedro Lessa foi o relator de processos de dez candidatos.

Além da Comissão de História, Pedro Lessa também foi indicado pelos consócios para apresentar alguns estudos em sessões ordinárias ou extraordinárias, a saber: a alocução sobre a data de Treze de Maio (1912), a homenagem a Francisco Adolfo de Varnhagen (1916), o Laudo Definitivo (1918) e o estudo a respeito do bicentenário de Philippe dos Santos (1921). O breve estudo sobre a história da escravidão no Brasil, Treze de Maio, não foi nem publicado na revista nem aparece nas atas e o estudo do bicentenário de Philippe

\footnotetext{
${ }^{2}$ Atingiria a classe de sócio honorário somente o sócio correspondente ou efetivo com, no mínimo, dez anos de filiação ao IHGB que tivesse realizado trabalhos relevantes para o Instituto (GUIMARÃES 2007).

${ }^{3}$ Essas informações foram retiradas das atas do período compreendido entre os anos de 1907 e 1920.
} 
dos Santos foi apresentado pelo sócio Jonathas Serrano, pois Lessa estava muito doente e não pôde realizá-lo. Os outros dois trabalhos - a homenagem a Francisco Adolfo de Varnhagen e o Laudo Definitivo - encontram-se registrados nas atas da revista do IHGB. O primeiro trabalho foi apresentado na noite de 17 de fevereiro de 1916 para comemorar o centenário de nascimento de Varnhagen (esse trabalho de Lessa recebeu, no ano seguinte, o prêmio de Conselheiro Olegário); e o segundo, o texto Laudo Definitivo, resultou da solução dada por Max Fleiüss para resolver a celeuma iniciada por Oliveira Lima e Gonçalves Maias, que divergiam a respeito da data comemorativa da Confederação do Equador. Os pareceres, o texto sobre Francisco Adolfo de Varnhagen e o Laudo Definitivo, são vestígios deixados por Pedro Lessa que resistiram ao tempo.

Para analisar todo esse material deixado por Pedro Lessa recorro a Michel Foucault (2006) para pensar a categoria autor. Foucault, ao refletir a respeito dessa categoria, não se preocupou com as análises sociológica e antropológica que são atribuídas ao indivíduo que escreve e assina o seu nome em um texto. A reflexão oferecida pelo filósofo francês consiste em uma análise do funcionamento de um determinado discurso em uma dada sociedade e o valor dado a determinado autor para que esse ou aquele discurso circule. Compreendeu, desse modo, que o indivíduo que escreve exerce a função autor. Porém, essa aproximação de Foucault é limitada; diferentemente do filósofo, selecionei apenas os textos assinados por Pedro Lessa; a função autor me possibilita examinar qual função Pedro Lessa exerceu no Instituto Histórico e Geográfico Brasileiro. Compreendendo que a História no Brasil não era uma disciplina autônoma e que Pedro Lessa era um juiz do Supremo Tribunal Federal, interrogo: quem trabalha pela História no IHGB, o juiz Pedro Lessa ou o historiador Pedro Lessa?

\section{Narrador ou Juiz-relator?}

Durante o tempo em que integrou a Comissão de História, Pedro Lessa dividiu o espaço com outros sócios ${ }^{4}$ - Benjamin Franklin Ramiz Galvão (1907 a 1911), Visconde de Ouro Preto (1907 a 1911), Bernardo Teixeira de Morais Leite Velho (1907 a 1909), Antônio Jansen do Paço (1907 a 1911), Emydio Dantas Barreto (1910 a 1911), Clóvis Beviláqua (1913, 1915, 1917 a 1919), Augusto Olympio Viveiros de Castro (1913, 1915, 1917 a 1919), Luiz Gastão d'Escragnolle Doria (1913, 1915, 1917), João da Costa Lima Drummond (1913), Alfredo Valladão (1915), Laudelino Freire (1917 a 1918), Basílio de Magalhães (1918 a 1919) e Jonathas Serrano (1919) -, ora acompanhando o relator ora sendo o relator. Lessa foi indicado onze vezes à relatoria e analisou os trabalhos de João Coelho Gomes Ribeiro (1908), João Batista de Moraes (1909), D. Agustin de Védia (1910), Ataulfo Nápoles de Paiva (1912), Enéas Galvão (1913), Miguel Calmon du Pin e Almeida (1913), José Juan Biedma (1915), Alfredo Pinto Vieira Mello (1915) e João Martins Carvalho Mourão (1915). Apesar de ser indicado

\footnotetext{
${ }^{4}$ As datas entre parênteses, de Benjamin Franklin Ramiz Galvão a Jonathas Serrano, correspondem aos anos em que os sócios dividiram as cadeiras da Comissão de História com Pedro Lessa. Em 1914, 1916 e 1920 não foram registradas nas revistas do IHGB as Assembleias Gerais; por esse motivo, não tem como saber quais foram os sócios eleitos.
} 
para analisar os trabalhos de Velloso Rebello e de Manuel Porfirio de Oliveira, Lessa não o fez, e a relatoria do primeiro foi transferida para Basílio de Magalhães e a do segundo para Clóvis Beviláqua. O inverso também ocorreu, a obra de Sousa Docca (1921) estava sob a relatoria de Manuel Cicero Peregrino da Silva e foi transferida para Lessa. Nove dos dez pareceres realizados por Pedro Lessa foram registrados em ata, apenas o parecer acerca da obra de D. Agustin de Védia não consta em ata e também não seguiu para a Comissão de Admissão de Sócios.

Diante desses pareceres a palavra relator chama-me atenção; afinal, relatar é uma ação do historiador? Intuo que ela pertença à área do Direito. Recorro, então, a quatro dicionários ${ }^{5}$ e consulto o verbete. O primeiro dicionário que examino é o Dicionário da Língua Brasileira, ${ }^{6}$ organizado por Luiz Maria da Silva Pinto (1832, p. 916), nesse dicionário, relator é: "o que relata algum fato" ou "Juiz relator, o que expôs a causa perante os outros Juízes seus colegas". No segundo dicionário, Grande Dicionário Português ou Tesouro da Língua Portugueza,7 de Frei Domingos Vieira (1874, p. 177), entende-se por relator: "Pessoa que refere, historiando" ou "homem que refere, expondo a causa ante os juízes: ordinariamente dizemos o juiz relator, o que assoma o feito quanto aos fatos, e provas, e vota primeiro direito e sentença". O Dicionário Contemporâneo da Língua Portugueza, ${ }^{8}$ o terceiro dicionário que consulto é de autoria de Caldas Aulete (1881, p. 1512); nele o verbete relator significa "a pessoa que relata, que refere vocalmente ou por escrito todas as circunstâncias e fundamentos Q42 de um projeto de lei, de um processo, de um projeto, etc.", mas também "Juiz relator, aquele a quem num tribunal coletivo é distribuído, em primeiro lugar, um processo para fazer o relatório fundamentando o seu voto". Por fim, o último dicionário que exploro é o Novo Dicionário da Língua Portuguesa, ${ }^{9}$ escrito por Candido de Figueiredo (1899, p. 437); nele, relator é "aquele que relata. Aquele que redige um relatório ou o parecer de uma comissão ou assembleia. Aquele que refere ou narra; narrador".

Os quatro dicionários permitem que observe duas figuras para aquele que exerce a relatoria, o narrador e o juizrelator. O narrador é aquele que relata algum fato, historia, avalia um processo, redige um relatório ou um parecer;

\footnotetext{
${ }^{5}$ Compreendendo que Pedro Lessa viveu entre meados do século XIX e começo do século XX, foram consultados os dicionários em Língua Portuguesa que circularam no período.

${ }^{6}$ Luiz Maria da Silva Pinto (1770/80?-1869), dono da Tipographia de Silva, autor e tipógrafo do Dicionário da Língua Brasileira. O nome do dicionário chamou a atenção da pesquisadora Ivana Stolze Lima; ao estudá-lo, ela descobriu que, devido ao nome do dicionário, as pessoas achavam que o dicionário traria verbetes dos índios e não da língua portuguesa.

${ }_{7}$ Adolpho Coelho e Theophilo Braga foram dois dos editores do Grande Dicionário Português ou Tesouro da Língua Portugueza, juntos organizaram e ampliaram o manuscrito deixado por Frei Domingos Vieira (1775-1857). O dicionário foi publicado em 5 volumes, entre 1871 e 1874.

${ }^{8}$ Francisco Júlio de Caldas Aulete (1826-1878) é o autor do Dicionário Contemporâneo da Língua Portugueza. Caldas Aulete tinha a intenção de criar um dicionário portátil e com palavras que fossem do domínio da conversação. A obra tem dois volumes: no primeiro, os verbetes vão de $A$ a I e no segundo, de I a Z.

9 O Novo Dicionário da Língua Portuguesa foi organizado por Antônio Cândido de Figueiredo (1846-1925). A obra tem dois volumes.
} 
o juizrelator é aquele que expõe as causas perante aos colegas, é o primeiro a fundamentar o voto ou a sentença. Então, apropriando-me da categoria autor, interrogo-me: quando trabalhava como relator no IHGB, Pedro Lessa estaria mais próximo à figura do narrador ou à figura do juiz relator? Ou seja, ele apenas relatou alguns fatos, historiando, avaliando e redigindo um parecer ou foi o primeiro a fundamentar, na Comissão de História, o voto ou a sentença? Para responder à questão examinarei aqui um dos nove pareceres de Pedro Lessa, escolhi um dos casos mais delicados entre os que estiveram nas mãos de Pedro Lessa, o caso do argentino José Juan Biedma. ${ }^{10}$

José Juan Biedma pleiteou uma vaga de sócio correspondente no IHGB. A categoria de sócio correspondente previa a admissão de estrangeiros, mas Basílio de Magalhães, o sócio do Instituto que analisou a obra de Biedma junto com o relator Pedro Lessa e com Clóvis Beviláqua, apresentou uma restrição à sua admissão; para Magalhães, o autor manifestava sobejamente em suas obras o antibrasileirismo. Já o relator Lessa (1915, p. 701) iniciou o parecer afirmando que reconhecia "o ilustre professor de História do Collegio Nacional de Buenos Aires, sr. José Juan Biedma", pois ele muito merecia "ser eleito sócio correspondente do Instituto Histórico e Geográfico Brasileiro". Em seguida, utilizou uma tática frequentemente por ele usada no plenário do Supremo Tribunal Federal, o constrangimento. ${ }^{11}$

No parecer, Pedro Lessa (1916, p. 702) apresentou o livro Atlas Histórico de la Republica Argentina, classificou-o "como trabalho didático" e não colocou em questão "a excelência do método, a clareza, a concisão, o interesse das elucidações geográficas e históricas". Em seguida, Lessa informou que Biedma, o "indefesso trabalhador", também estudava as biografias de "seus homens ilustres" e ofereceu aos sócios um excerto da biografia de Bartolomeu Mitre Martinez (1821-1906):

Quando a posteridade formular seu juízo sobre o tenente-general Bartolomeu Mitre, com prévio estudo profundo de sua vida e com critério filosófico de Plutarco ou Tácito, muitos poucos serão os americanos comparáveis ao ilustre Argentino. Militar esclarecido, que realizou façanhas estratégicas como a passagem do Paraná, pelo exército aliado, e da campanha de Quadrilátero na guerra com o Paraguai, elevou-se à altura dos generais de gênio; estadista não igualado em sua pátria, realizou o que ninguém lograra - a união das províncias argentinas sob o regime federativo-nacional, e deu rumos superiores a política interna e externa da Republica; historiador e publicista de reputação europeia; cidadão de virtudes exemplares, que no apogeu do poder como no seio do país tem inspirado sempre aos seus compatriotas um carinho intenso, de que só há um exemplo no que Washington inspirou aos de sua nação; Mitre é um conjunto de qualidades e feitos ilustres, que a História imparcial colocará entre as primeiras grandezas do século XIX (LESSA 1916, p. 702-703).

\footnotetext{
${ }^{10}$ José Juan Biedma (1864-1933) foi indicado para sócio no dia 20 de abril de 1914. O parecer da Comissão de História foi entregue no dia 23 de agosto de 1915.

${ }^{11}$ No plenário, Pedro Lessa usava um leque preto e portava-se combativamente, discutia e até constrangia seus colegas com ironias (RODRIGUES 1991).
} 
O trecho escolhido por Pedro Lessa provava o "exaltado patriotismo" de Biedma, mas o relator também sabia que esse mesmo sentimento patriótico fez com que "algumas vezes" o historiador argentino diminuísse "os homens e feitos das outras nações", como havia acontecido em relação ao Brasil em outra obra do autor, Crônica histórica del Rio Negro de Patogones. Nesse momento, o relator preferiu não transcrever excerto algum desse outro trabalho. Usando um tom de dúvida, Lessa (1916, p. 703) afirmou: "não sabemos si é preferível censurar tais senões do ilustre cronista, ou apresentá-los aos nossos patrícios como um espelho em que devem mirar-se, para corrigir os defeitos opostos de que padecem". Por fim, Pedro Lessa o aprovou por compreender que o historiador argentino era um vulgarizador da Geografia e da História de seu país e, para encerrar seu parecer, elaborou uma pergunta constrangedora: "que outro melhor título poderia ele exibir à eleição do Instituto Histórico e Geográfico Brasileiro?" (LESSA 1916, p. 703).

Clóvis Beviláqua, por seu turno, compreendia, assim como Pedro Lessa, que o historiador argentino sendo um patriota somente poderia exaltar a história de sua própria nação, por isso subscreveu o parecer do relator e julgou importante lembrar que Biedma, ao saudar o chanceler brasileiro, o general Lauro Müller, destacou as relações de amizade entre Brasil e Argentina:

[...] recordou [Biedma] a ação conjunta do Brasil e da Argentina na ereção da República Oriental do Uruguai, considerando esse fato "evocador do começo de uma amizade internacional consolidada, no tempo, por grandes fatos históricos e recíprocos interesses, a qual irradiará, calor e luz na alma e na consciência dos povos da América, que nos contempla" (BEVILÁQUA 1916, p. 703).

Afinal, o relator Pedro Lessa, o autor do parecer, aproximou-se mais da figura do narrador ou do juiz relator? Lessa é o narrador quando tecnicamente descreve e avalia o candidato e sua obra, mas também exerce a voz de juiz relator quando vestindo a toga expõe seus argumentos aos demais colegas fundamentando o seu voto. Saber narrar e julgar eram atributos necessários ao relator.

Talvez por ter os atributos de um relator que Lessa foi indicado por Max Fleiüss e Roquete-Pinto para homenagear Francisco Adolfo de Varnhagen (18161878) (ACTAS DAS SESSÕES DE 1915 1916, p. 648). Tal missão não era tão fácil, afinal, o homenageado era conhecido pela sua forte personalidade, pelas muitas desavenças que teve em vida e pelas muitas críticas que recebeu mesmo após a sua morte. Além disso, Pedro Lessa não seria o primeiro a narrar a vida e a obra de Varnhagen: naquela ocasião havia a biografia escrita por José Carlos Rodrigues (1844-1923), o discurso fúnebre de Joaquim Manoel de Macedo (1820-1882), os artigos de João Capistrano Honório de Abreu (1823-1927) e o elogio de Manuel de Oliveira Lima (1867-1928) (GUIMARÃES 2011).

José Carlos Rodrigues escreveu a biografia de Varnhagen e publicou no jornal $O$ Novo Mundo que passou a editar quando, após concluir o curso de Direito em São Paulo, foi morar em Nova Iorque. Essa biografia, publicada em 
1873, contou com uma carta de agradecimento do biografado (GUIMARÃES 2011). Outro a escrever a respeito de Varnhagen foi Joaquim Manuel de Macedo. Como sócio do IHGB, coube a Macedo a incumbência de narrar as memórias dos membros do Instituto falecidos no ano de 1878. Ao recordar de Varnhagen, o autor fez críticas aos seus juízos sobre os indígenas, mas também lembrou de suas colaborações - documentos e artigos - e o denominou "homem-monumento" (GUIMARÃES 2011). Capistrano de Abreu, por sua vez, escreveu dois artigos: o primeiro intitulado "Necrológio de Francisco Adolfo de Varnhagen" foi publicado no Jornal do Commercio, em 1878, e o segundo, "Sobre o Visconde de Porto Seguro", foi publicado na Gazeta de Notícias, em 1882. Apesar das críticas de Capistrano de que faltava a Varnhagen o domínio da Sociologia e de que sua escrita estava comprometida com a visão do Estado Imperial, Capistrano comparou o historiador a um bandeirante, pelo seu caráter fundador da historiografia. No artigo de 1882, o tom empregado foi outro, Capistrano de Abreu criticou a forma narrativa uniforme que Varnhagen adotou em períodos distintos e argumentou que era necessário pensar a história do Brasil distribuindo-a em temas e delimitando as diferentes épocas (OLIVEIRA 2013; ANHEZINI 2015). Manuel de Oliveira Lima, o último dos autores mencionados a escrever a respeito de Varnhagen, rememorou a ocasião de posse de Varnhagen na Academia Brasileira de Letras, em 1903. Oliveira Lima o escolheu como patrono da cadeira 39 e narrou a vida de Varnhagen, o historiador do Brasil, em relação à sua própria vida, ou seja, "tornou a biografia do homenageado uma autobiografia" (MALATIAN 2001, p. 175).

Cada um desses estudos elaborou um Varnhagen diferente: Rodrigues elevou os feitos de Varnhagen ainda em vida, Macedo teceu críticas aos juízos de Varnhagen sobre os indígenas, mas também o transformou em "homemmonumento", Capistrano de Abreu identificou o que faltara na História Geral do Brasil, criando o seu lugar na historiografia brasileira, e Oliveira Lima usou Varnhagen como um espelho para relatar suas próprias experiências. E Pedro Lessa, qual Varnhagen criou em 1916? Como falou dos descompassos do historiador do Brasil em uma cerimônia de homenagem? O autor Pedro Lessa precisou vestir a toga?

\section{Estudo ou absolvição?}

Pedro Lessa (1917, p. 614) iniciou o seu texto com uma citação de Nicolau Maquiavel, na qual se lê: "a fortuna dispõe da metade de nossas ações, e confia a outra metade ao nosso livre arbítrio". Lessa não partilhava da ideia de predestinação, por essa razão sugeriu aos ouvintes e, posteriormente, aos leitores que substituíssem as palavras fortuna por "condições e circunstâncias da vida" e livre arbítrio por "vontade". Tais mudanças deixariam a frase de Maquiavel assim: as condições e circunstâncias da vida dispõem da metade de nossas ações, e confiam a outra metade à nossa vontade. Essa seria a chave para entender a vida e a obra de Varnhagen, Lessa (1917, p. 615) explicou que os dois fatores, condições e vontade, levaram Varnhagen "desde moço aos estudos necessários à realização da sua tarefa de historiador". Afinal o autor de História 
Geral do Brasil era "ainda jovem" quando iniciou a "carreira diplomática", a oportunidade possibilitou-Ihe viajar por várias "cidades da Europa e da América", já a sua vontade o levou a "frequentar bibliotecas, arquivos e museus" e consultar "livros, mapas, autógrafos, inscrições, medalhas, moedas, gravuras, pinturas e toda espécie de documentos". Usufruindo das condições e impulsionado pelas vontades, desse modo Varnhagen assumiu a responsabilidade de ser o "primeiro a escrever a história do seu país" (LESSA 1917, p. 614-615).

O trabalho do "iniciador da Historiografia brasileira" era, contudo, criticado por não "refletir" sobre a História. Pedro Lessa, sem nomear os autores da crítica, denominou-a de "imperdoável contrassenso" com aquele que escrevera a história nacional "de mais de três séculos" e justificou que, na época e no "ambiente que o cercaram, não se podia fazer com uma regular observância dos preceitos da Historiografia", ou seja, "não lhe era possível adotar os rigorosos processos e seguir os fecundos preceitos da metodologia, que só mais tarde os historiadores e professores da Alemanha e da França divulgaram" (LESSA 1917, p. 615-617). Lessa argumentou que o historiador seguira os preceitos de sua época, buscara os documentos e narrara os fatos, afinal apenas mais tarde os historiadores alemães e franceses difundiram o método interpretativo. Para fundamentar seu argumento, Lessa lembrou-se dos conselhos de "um mestre da Historiografia contemporânea", Ernst Bernheim. Não se sabe quais conselhos eram esses e nem a qual obra do historicista Lessa se referiu, no entanto, citar Bernheim o autorizou a afirmar que:

[...] o historiador pátrio, por necessidade lógica de seu espírito, feito de exatidão e de severidade, amor a verdade e a justiça, se esforçou, nos limites do possível, de acordo com os meios que lhe facultavam, por observar os cânones da Heurística, procurando penetrar o sentido dos livros e de todos os documentos sem os quais não se podia estudar as fontes da nossa História, adquirir ideias exatas a respeito da nossa arte rudimentar e de todas as nossas antiguidades (LESSA 1917, p. 617).

A escrita da História de Varnhagen seria feita de exatidão e severidade, amor à verdade e à justiça. Além desse nobre sentimento para com a história pátria, Pedro Lessa lembrou a todos de que o historiador brasileiro não tinha "nenhum modelo, nenhum antecessor, nenhum guia", afinal "nenhum brasileiro ou português escrevera antes um só livro, a que quadrasse o título de História do Brasil". Lessa asseverou que antes de Varnhagen existiram os cronistas Pero de Magalhães Gandavo (1540-1580), José de Anchieta (15341597), Manuel da Nobrega (1517-1570) e Gabriel Soares de Sousa (15401591), mas esses "nunca poderiam pretender o título de historiador". Houve também aqueles que escreveram "sobre assuntos especiais e muito restritos", como o Frei Antônio de Santa Maria Jaboatão (1695-1779), autor de Crônica dos Frades Menores da Província do Brasil, Pedro Taques de Almeida Pais Leme (1714-1777), autor de Genealogia das principais famílias de S. Paulo, Frei Gaspar da Madre de Deus (1715-1800), autor de Memórias para a História de uma capitania, José de Sousa Azevedo Pizarro e Araújo (1753-1830), autor de 
Memórias históricas do Rio de Janeiro e das províncias anexas à jurisdição do Vice-Rei do Estado do Brasil, dedicadas a El-Rei Nosso Senhor D. João VI, e Luiz Gonçalves dos Santos (1767-1844), autor de Memória para servir à História do reino do Brasil. Os materiais produzidos por esses últimos, segundo Lessa, "apenas proporcionaram ao historiador alguns subsídios, que só podiam ser aproveitados depois de uma rigorosa seleção" (LESSA 1917, p. 624). Em se tratando da obra História da América Portuguesa, de Sebastião de Rocha Pitta (1660-1738), o próprio Varnhagen não considerava uma obra de História; Pedro Lessa reescreveu a sua "apreciação":

\begin{abstract}
A História de Pitta, que ainda hoje se aprecia pelo seu colorido poético, bem que omissa em fatos essenciais destituída de crítica e alheia a intenções elevadas de formas ou de melhorar o espirito nacional, fazendo avultar sem falar à verdade, os nobres exemplos dos antepassados, serviu de muito, por algumas de suas próprias exagerações, para recomendar à metrópole o Brasil. O autor não recorreu sempre, é verdade, às mais puras fontes da História; era mais imaginativo que pensado; mais poeta e admirador do belo do que crítico, vassalo da razão e escravo das provas autenticas; e querendo ser o Tito Lívio da pátria, narrando os fatos do Brasil, tinha menos presente o seu passado que tudo quanto sucedera em Roma e Cartago (LESSA 1917, p. 625).
\end{abstract}

Além dos cronistas e dos autores das histórias restritas, Pedro Lessa não deixou de abordar um historiador estrangeiro que escreveu a História do Brasil antes de Varnhagen, o inglês Robert Southey (1774-1843). Lessa também conhecia as críticas de Taine e Victor Hugo a respeito do estilo narrativo de Southey; para esses autores, o historiador inglês era muito imaginativo e escrevia curiosidades pitorescas. Lessa somou essas críticas aos erros inadmissíveis para um historiador do Brasil e apresentou alguns exemplos da obra de Southey como prova do desconhecimento do território brasileiro:

Primeiro historiador do Brasil não pode ser quem, ao compor a História do Brasil, num capítulo descreve a fundação de Buenos Aires por d. Pedro de Mendoza e tomada de Assunção por Ayola; noutro narra como ao adiantado d. Pedro de Mendoza sucedeu no Prata Cabeza de Vaca; num terceiro conta-nos que outro espanhol fundou o Leste de Chuquiasca, na Bolívia, Santa Cruz de laSierra; mais adiante refere longamente a lutas do Bispo do Paraguai, d. Bernardino de Cardenas, com o governador Hinostrósa e com os Jesuitas, para depois ainda mais extensamente relatar certos tumultos no Paraguai, a usurpação parte do domínio espanhol por Antequera, o suplicio deste, a expulsão dos jesuítas de Assunção, e outro fatos da História do Brasil (LESSA 1917, p. 626-627).

Continuando com o tom irônico, Lessa afirmou que para "quem lê certos capítulos da História de Southey, as noções que ficam da Geografia do Brasil são tão exatas como as adquiridas por quem converse com um francês contemporâneo acerca do mesmo assunto". Logo, Lessa (1917, p. 627) provou a "inferioridade da sua História em relação à de Varnhagen", mas o seu senso de justiça e os conselhos de Bernheim levaram-no a ponderar, lembrando que na "qualidade de estrangeiro" Southey fez o melhor que podia para a sua época. 
Após justificar o porquê Varnhagen era o "pai da historiografia brasileira", Pedro Lessa voltou-se para as críticas feitas pelo monarquista falecido Eduardo Paulo da Silva Prado (1860-1901) e pelo consócio do IHGB Francisco Inácio Marcondes Homem de Melo (1837-1918) à obra do Visconde de Porto Seguro. Eduardo Prado, ao realizar a Conferência Anchietinas, teria dito que Varnhagen "mutilou a História" escrevendo "uma obra pálida e sem vida" (LESSA 1917, p. 630), e o Barão Homem de Melo negou o título de historiador a Varnhagen, "rebaixando-o à categoria de 'um medíocre cronista"" (LESSA 1917, p. 647).

Afirmar que a história de Varnhagen era "pálida" e "sem vida", como fez Eduardo Prado, remetia a outra crítica partilhada por seus contemporâneos, aquela de que o historiador do Brasil não seguiu os conselhos de Carl Friedrich Phillipp von Martius (1794-1868). Para examinar a polêmica, Lessa apresentou a tese das três raças de von Martius em Como se deve escrever a História do Brasil e, dessa maneira, pôde destacar a orientação de von Martius a respeito do tratamento a ser conferido a cada raça, bem como a expôs a indicação do naturalista de que a narrativa histórica deveria se parecer "com um epos". Para explicar o que isso significava, Lessa (1917, p. 630) transcreveu as palavras de von Martius segundo as quais epos era uma narrativa composta "com todo o amor e todo zelo patriótico, com aquele fogo poético próprio da juventude, o que não exclui a aplicação e profundeza de juízo e firmeza de caráter, peculiar à idade madura e varonil". Para Pedro Lessa (1917, p. 629), os conselhos de von Martius a respeito das três raças eram 248 "sensatos", "óbvios" e "necessários", por isso seria impossível "a qualquer espírito medianamente lúcido e instruído compor uma História do Brasil sem os observar". Tais conselhos foram respeitados por Varnhagen, o que ele não fez foi transformar a História em epos.

De qualquer modo, para provar que o historiador era vítima de acusações injustas, Lessa (1917, p. 630) recordou que von Martius foi botânico e estudou "carinhosamente a sua especialidade, as suas orquídeas, as suas citamíneas, as suas passifloras", mas que, ao se afastar do "domínio dos seus estudos prediletos", aconselhou os historiadores a escreverem um "poema heroico" da História do Brasil; ideias que, possivelmente, recordara das "leituras clássicas da sua adolescência", principalmente dos escritos de Heródoto, de Xenofonte, de Tito Lívio ou de Salustio, mas Varnhagen, que publicou a sua obra em meados do século XIX, não poderia se servir desses modelos.

Não the podiam servir de modelos os novos capítulos, dedicados às nove Musas, e recheados de lendas e fábulas, da História de Heródoto, nem aquelas descrições de cenas da mais enaltecida moral, fantasiadas de Xenofonte na História de Cyro, nem aqueles equívocos, erros e falsidades, nem aquelas brilhantes e eloquentíssimas arengas, que abundam nas Decades de Tito Lívio, nem aquelas páginas admiráveis que Salustio escreveu só para exibir o seu estilo magnifico (LESSA 1917, p. 630-631).

Dessa forma, Pedro Lessa argumentou que o Visconde de Porto Seguro, assim como os historiadores da França, da Inglaterra e da Alemanha, era um 
homem de seu tempo que tinha "a primeira qualidade do historiador" para aquela atualidade, "a fidelidade nas descrições, a verdade, a exatidão". De acordo com o jurista brasileiro, o modelo de historiador francês era Fustel de Coulanges (18301889), pois ele estava rodeado "das mais seguras informações", eliminava "todo elemento subjetivo", abstraía "todas as minudencias dispensáveis" e excluía "todas as anedotas". Um modelo da historiografia inglesa era Thomas Babington Macaulay (1800-1859), cuja "principal preocupação é a verdade, é ser exato e preciso". Na Alemanha, Leopold von Ranke (1795-1880) retratou "exatamente os atos individuais dos homens e os fatos políticos", Jacob Burckhardt (18181897) consagrou-se ao "desenhar os lineamentos gerais que caracterizam uma civilização", Karl Marx (1818-1883) esforçou-se em "penetrar os motivos sociais dos atos coletivos e as causas que engendram os vários tipos de homens" e Eduardo Meyer (1855-1930) apresentou um quadro "complexo e orgânico" de "toda a antiguidade". Com esses exemplos, Pedro Lessa buscou demonstrar que Varnhagen tinha "um espírito sério e instruído", assim como o tinham os historiadores franceses, ingleses e alemães, e, por isso, era impossível adotar aquele antigo modelo de História orientado por von Martius, o modelo da história mestra (LESSA 1917, p. 631).

Para reforçar o argumento de que o injustiçado Varnhagen guiava-se pela verdade e amor à pátria, Pedro Lessa recorreu ao prólogo da História Geral do Brasil e reescreveu o excerto no qual Varnhagen descrevera sua compreensão da narrativa da História:

Convencido igualmente de que a verdade é a alma da História, que só ela pode oferecer harmonia eterna entre os fatos narrados, que a verdadeira crítica da verdade histórica não se pode aquilatar senão pela concordância nos incidentes, não nos poupamos a nenhum esforço, a fim de remontar as fontes mais puras. [...] procurando sempre escrever antes, um livro útil e próprio a estimular o trabalho e a prática das boas ações, do que puramente ameno e destinado à simples distração (LESSA 1917, p. 632-633).

A partir dessas afirmações, Lessa considerou injusta a tentativa do Barão Homem de Melo de chamar Varnhagen de cronista e, contra essa injúria, ironizou:

Crônica de mais de três séculos da vida de uma nação, feita metodicamente, com a reconstrução meticulosa, e tão documentada quanto possível, de todos os fatos de ordem histórica; crônica escrita depois de muitos anos de ininterruptas pesquisas e da aquisição de abundantes conhecimentos das ciências [...] não é Crônica; é História (LESSA 1917, p. 647).

Pedro Lessa desmontou as críticas de Eduardo Prado e do Barão Homem de Mello com o argumento de que Varnhagen era um homem do século XIX e, assim sendo, ele seguiu, assim como outros historiadores, as regras de seu tempo; não Ihe cabia, portanto, seguir os preceitos da história mestra ou escrever uma crônica, por isso escreveu uma obra cívica e buscou narrar uma História que fosse "útil" e estimulasse o "trabalho" e a "prática de boas ações". Porém, essas não foram as únicas acusações dirigidas por Eduardo Prado e 
pelo Barão Homem de Melo; o primeiro afirmou que Varnhagen menoscabara "todas as heroicidades, da de Anchieta e da de Tiradentes" (LESSA 1817, p. 636), e o segundo acusou o autor da História Geral do Brasil de amesquinhar "Colombo, e lhe arrancou da fronte os louros imarcescíveis" (LESSA 1917, p. 645) e considerou desnecessária a dedicação de Varnhagen à invenção do padre Bartholomeu Lourenço de Gusmão.

Tal afirmativa de Eduardo Prado estimulou Pedro Lessa a investigar em que momento o injustiçado historiador teria menoscabado Padre Anchieta. Pedro Lessa, então, reescreveu as breves linhas que Varnhagen dedicou ao personagem histórico, narrou primeiramente a chegada de Anchieta, o "zeloso Jesuíta", em terras brasileiras e o seu projeto de fundar um colégio; em seguida, retratou o momento em que Anchieta fora feito refém pelos indígenas, e destacou que tal acontecimento levou o jesuíta a compor um poema em latim de seis mil versos em homenagem à vida da Virgem (LESSA 1917, p. 636-637). Após apresentar as palavras de Varnhagen, Pedro Lessa (1917, p. 637) argumentou que o historiador brasileiro fora "demasiadamente lacônico" e que o "fundador da cidade de São Paulo [...] bem merecia de um historiador paulista mais algumas linhas", ou seja, mesmo reconhecendo que Varnhagen fora lacônico, o juiz Lessa sentenciou que a vida de Anchieta deveria ser objeto de um "historiador paulista" e não do historiador do Brasil.

Além de reescrever as palavras de Varnhagen a respeito de Padre Anchieta, Pedro Lessa as comparou com a narrativa do historiador inglês Robert Southey. 2.50 o inglês narrara os momentos de descanso de Anchieta: "Para resguardá-lo do sol the formavam dossel sobre a cabeça as aves voadoras"; as cenas de quando o jesuíta precisava pescar: "Nas redes se lhe vinham meter os peixes, quando deles carecia"; os momentos nos quais Anchieta precisava introduzir-se na mata: "As feras da floresta o acompanhavam nas jornadas servindo-Ihe de escolta" (LESSA 1917, p. 638). Com esses breves exemplos, Lessa (1917, p. 639) ironicamente sugeriu que Eduardo Prado preferia as crônicas de Southey às "árduas escavações do passado" de Varnhagen.

Eduardo Prado foi demasiadamente severo nas críticas anteriores, mas considerar que Varnhagen desdenhara Tiradentes foi para Lessa "ainda mais duro, para não dizer injusto". Afinal, segundo o jurista brasileiro, o historiador brasileiro transformara "Joaquim José da Silva Xavier, alcunhado Tiradentes" em um revolucionário; nas palavras de Varnhagen: "desde que na alma Ihe caiu a primeira centelha a favor da ideia de independência, lavrou o incêndio por tal forma, que não se pode mais apagar". Em seguida, Lessa transcreveu a passagem em que Varnhagen dedicara-se a narrar o sentimento patriótico de Tiradentes, desde as ações "em favor da independência" da pátria até o momento de sua sentença (LESSA 1917, p. 640-641). Eis o trecho no qual Lessa provou a "glorificação de Tiradentes" por Varnhagen:

Do alferes Silva Xavier sabemos que ouvira a sentença com toda a serenidade; e que, estimava vir a pagar as culpas daqueles que ele havia comprometido. Por essa forma ele se adiantou a aceitar para si a responsabilidade desta nobre tentativa do martírio que hoje lhe confere 
a posteridade. O dia 21 de abril veio ser designado para o do seu suplicio no Rio de Janeiro (LESSA 1917, p. 642-643).

Tiradentes narrado por Varnhagen, de acordo com as análises de Lessa, era um personagem patriótico e corajoso que lutou pela independência da pátria. Quem menosprezou, conforme o jurista brasileiro, a heroicidade do personagem histórico fora Robert Southey, pois o "historiador estrangeiro" não escrevera nenhuma "palavra que lembrasse a coragem, a serenidade e a grande e incontestada nobreza de ânimo" (LESSA 1917, p. 644). Desse modo, Pedro Lessa mais uma vez ironizou Eduardo Prado:

Não sei se foi nas páginas meramente descritivas, ou nas justas e irrefutáveis considerações que o bom senso de Varnhagen faz sobre os fatos narrados, que a perspicácia de Eduardo Prado descobriu qualquer menoscabo da heroicidade de Tiradentes, ou a intenção de deprimir a grandeza e a beleza dos feitos da nossa história (LESSA 1917, p. 643-644).

Após provar que Varnhagen não desqualificou nem padre Anchieta nem Tiradentes, Pedro Lessa voltou-se para a primeira acusação do Barão Homem de Melo: o historiador do Brasil teria amesquinhado Colombo. Para o juiz brasileiro, esse seria "um delito" "hediondo" e por isso a acusação merecia "um meticuloso exame" (LESSA 1917, p. 645). Lessa, dessa vez, não recorreu ao texto de Varnhagen, preferiu consultar Manuel Pinheiro Chagas (1842-1895), o historiador português do descobrimento, e transcreveu algumas de suas "notáveis erudições", como o Imago Mundi (1483), do cardeal Pierre d'Ailly:

[...] "códice venerável" que foi o catecismo onde o nauta [Colombo] ousado adquiriu talvez a maior parte dos seus conhecimentos cosmológicos"; em repetir a asseveração incontestável de que "na errada persuasão de haver abicado ás costa da Ásia, havendo chegado a ela desde a Espanha sempre por mar, pelo rumo do Ocidente, morreu o grande homem, que verdadeiramente se pode dizer que consumou a obra começada por Alexandre, de pôr em comunicação reciproca o gênero humano" (LESSA 1917, p. 645).

Pedro Lessa comentou também as formulações de Alexander von Humboldt (1769-1859). O geógrafo argumentava que o "continente americano fora antes pelo lado setentrional visitado por naturais da Irlanda e da Islândia", por isso foi "preciso que os portugueses chegassem por mar à verdadeira Índia, para ficar sabendo que era esta a mesma Índia [...] e que a região descoberta por Colombo formava um continente diverso" (LESSA 1917, p. 646). Tais ideias dos autores comentados por Lessa possibilitaram ao jurista certificar-se de qual era a versão histórica de Colombo e argumentar que era dessa narrativa que Varnhagen partilhava.

Após apresentar as provas de que Varnhagen não amesquinhara o descobridor do continente americano, Pedro Lessa atentou para a outra crítica do consócio a respeito da "navegação aérea" e do "invento do padre Bartholomeu Lourenço de Gusmão". O Barão Homem de Mello considerava que eram "páginas 
acoimadas de impropria, destoante, indigna de um livro de História". Para Lessa, tal consideração consistiria em outra tremenda injustiça e, por isso, o juiz brasileiro transcreveu o trecho de Varnhagen dedicado ao episódio, salientando que o fragmento ocupou menos de uma página:

O problema da navegação aérea é tão antigo como a humanidade, e, si a raça humana não acabar, ela tem de resolver favoravelmente; e então sim, que as nações experimentarão uma verdadeira revolução, e ai daquelas que, tendo julgado a resolução do problema impossível, não se hajam preparado para aguentar os abalos e choques dessa revolução (LESSA 1917, p. 648).

No mesmo parágrafo, Varnhagen escrevera que os homens deveriam construir uma máquina capaz de voar com a ajuda do conhecimento científico, assim como o fizeram com a navegação marítima. Lembrara ainda da invenção do Padre Bartholomeu Lourenço de Gusmão que criou, a partir da observação dos pássaros, a "Passarola". Homem de Melo criticou tais argumentos de Varnhagen, ao passo que Lessa os avaliou como "uma página verdadeiramente profética", afinal os impactos da revolução da navegação aérea foram verificados com o advento da guerra; conflito que, mais tarde, foi denominado Primeira Guerra Mundial.

Nessa extensa defesa, apesar de demonstrar que não faltavam acusações injustas a Varnhagen, o jurista brasileiro não deixou de destacar o "delito máximo de Varnhagen", aquele "que todos os seus críticos Ihe imputam e nenhum the perdoa", e num tom de suspense e ironia questionou: "Será a falsa narração de algum dos fatos da História brasileira? Ou a indesculpável omissão de um acontecimento capital, ou decisivo? Ou a errônea interpretação de qualquer documento, ou qualquer fonte essencial da nossa História?" (LESSA 1917, p. 649). Ao que Lessa respondeu que não. O "delito máximo de Varnhagen", aquele imperdoável, era seu juízo "sobre a escravização dos índios e o tratamento a estes ministrados" (LESSA 1917, p. 650). O assunto era polêmico e dividia opiniões, por isso Pedro Lessa explicou que "as ideias de Varnhagen acerca dos nossos autóctones não eram de [...] Varnhagen. Faziam parte integrante do ambiente da época" (LESSA 1917, p. 655), ou seja, o "delito" não era do historiador brasileiro, mas sim do tempo.

Pedro Lessa aproveitou a ocasião para afirmar "os predicados" do historiador, seu "o amor à justiça e à verdade", adquiridos pela busca documental e pela organização dos fatos. Essa laboriosa missão, de acordo com Lessa, ajudaria as Ciências Sociais a compreenderem quem era o brasileiro e a derrubarem as outras visões cientificamente errôneas sobre o Brasil. Mesmo Varnhagen não sendo réu, Lessa, como um juiz, examinou as críticas endereçadas a ele e as julgou injustas, perdoou seus delitos ao considerar a época e as circunstâncias nas quais viveu o historiador e reafirmou o seu lugar como o pai da historiografia brasileira. Diferentemente de seus antecessores - Rodrigues, Macedo, Capistrano de Abreu e Oliveira Lima -, Pedro Lessa expôs um estudo que extrapolou as atribuições a ele conferidas pelo IHGB, na medida em que o juiz brasileiro 
não somente apresentou uma homenagem ao centenário de Varnhagen, mas também julgou e absolveu o historiador.

Dois anos e meio após a comemoração do centenário de Varnhagen, Pedro Lessa foi escolhido para ser o "árbitro" que decidiria a melhor data para comemorar a Confederação do Equador, dia 2 ou dia 24 de julho, encerrando, assim, a briga entre Gonçalves Maia, Oliveira Lima e Basílio de Magalhães. Os jornais, Diário de Pernambuco e A província, foram palco de uma extensa divergência, pois o jornalista Gonçalves Maia ficou enfurecido com a mudança da data comemorativa do dia 24 para o dia 2, sem que os historiadores apresentassem uma prova cabal. Para rebater as críticas do jornalista, Oliveira Lima justificou que o historiador interpretava os documentos, mas também analisava as conjecturas dos fatos. Basílio de Magalhães tentou, assim como Oliveira Lima, explicitar a pratica do historiador e publicou um parecer no Diário Oficial. Como a briga parecia não cessar, Max Fleiüss propôs nomear um árbitro para emitir a opinião definitiva sobre a questão, e assim, o Conde de Afonso Celso designou para esse fim o juiz Pedro Lessa (ANEXO 1919).

\section{Laudo ou sentença?}

Responsável por escrever o Laudo Definitivo a respeito da data comemorativa da Confederação do Equador, Pedro Lessa não dispunha de nenhum documento novo, logo examinou a discussão dos dois historiadores e do jornalista. Assim, no dia 2 de julho de 1918, em reunião ordinária do IHGB, Lessa (1919, p. 423) leu seu laudo, iniciando a sua reflexão com uma breve citação da História da independência do Brasilde Varnhagen: "a prover-se de munições, a juntar a tropa, a reforçar os arsenais e a fazer proclamações, uma aos brasileiros, outra às províncias do Norte, uma terceira aos baianos, todas estas em seu nome, e uma quarta aos mesmos baianos, assinada pelos - povos dos Províncias do Brasil". No trecho escolhido por Lessa, Varnhagen narrava o modo como Manuel de Carvalho Paes de Andrade organizara a revolução. A passagem fundamentou o argumento de que o evento foi "preparado durante alguns meses, cujas ideias propulsoras foram pouco a pouco infiltrando em várias províncias do norte do país"; proposição que nem Gonçalves Maia negara.

Pedro Lessa, "o árbitro desempatador", recordou em seguida os três documentos assinados por Paes de Andrade. A primeira proclamação foi feita no dia 1 de junho, "dirigida aos Pernambucanos", e por isso se excluiu "a ideia da confederação"; além disso, "nenhum dos contendores" reconheceu a data (LESSA 1919, p. 424). A segunda proclamação do dia 2 de julho dirigiu-se a todos os habitantes das províncias do norte do Brasil, clamou pela união dos brasileiros e é a data que Varnhagen reconheceu como o início do movimento ao afirmar: "Tirou por fim Paes de Andrade a máscara no dia 2 de julho, lançando as proclamações já preparadas, convidando todas as províncias do Brasil a formarem uma Confederação, que se chamaria do Equador" (LESSA 1919, p. 424). A terceira proclamação, por fim, espalhada pelo "chefe revolucionário [...] endereçada aos brasileiros, e sem data", terminou com "Viva a confederação do Equador" (LESSA 1919, p. 424-425). Além dos três documentos, havia outra 
data, a de 24 de julho, mas em relação a essa data "não se conhece proclamação alguma" e "não há documento algum". Após rápida observação sobre as datas e os documentos, Pedro Lessa reconheceu:

Temos consequentemente a 2 de julho uma proclamação cuja data ninguém põe em dúvida, proclamação em que o presidente de Pernambuco se insurge contra o Governo Imperial, assume franca e solenemente o papel de revolucionário, expondo a sua liberdade e a própria vida, e instiga as Províncias do Norte a constituírem "um governo supremo, verdadeiramente constitucional". É um ato formal de rebelião, há o início de uma perfeita revolução, e o fim desta só podia ser (sobre isto não é permitida nenhuma dúvida) a Confederação do Equador (LESSA 1919, p. 425).

Em seguida, Lessa (1919, p. 425) indagou: "Faltava alguma coisa para patentear que a proclamação de 2 de julho era o começo da revolução?". E ele respondeu que, segundo Gonçalves Maia, "faltava a denominação, que se lê no outro documento, a proclamação ulterior sem data, de Confederação do Equador". Nesse momento, Lessa (1919, p. 425) retomou o seu argumento inicial: "se todos os atos de Paes de Andrade foram praticados indiscutivelmente, e sem contestação de um só escritor pátrio, com o fito de se constituir essa tão anelada Confederação, a proclamação de 2 de julho só podia referir-se à Confederação do Equador". Para embasar a sua decisão, Lessa utilizou o texto de Varnhagen, mas também a lógica:

Escolher para comemorar esses acontecimentos da nossa História, a data de qualquer dos atos preparatórios, fora evidentemente um alvitre indefensável. Escolher a data de qualquer dos atos praticados "depois de proclamada e bem conhecida a revolução", é não menor absurdo. Não se devendo eleger para a comemoração do fato histórico, nem qualquer data em que a revolução ainda estava incubada, ainda se conservava em propaganda secreta, nem a data de qualquer fato ulterior ao dia, em que a revolução explodiu, e se corporificou em atos cometidos publicamente [...] (LESSA 1919, p. 425-426).

Valendo-se da lógica de que a revolução fora elaborada há muito tempo e que se tornara pública para todos os brasileiros no dia 2 de julho, Lessa argumentou que pouco importavam as conjecturas, como "indagar o momento, em que o Governo central foi informado", ou que existisse uma prova cabal que atestasse que o documento sem data era de 24 de julho. O que realmente deveria importar era o momento revolucionário que todos reconheceram como o seu início e quando, tomado pelo sentimento patriótico, Paes de Andrade convidara a todos os brasileiros a participarem. Eis o Laudo Definitivo de Pedro Lessa, que também poderia se chamar Sentença, afinal o Instituto Histórico e Geográfico Brasileiro deu-lhe poderes para encerrar uma divergência, e ele, como um historiador, apresentou os fatos e interpretou os documentos e, como um juiz, determinou que 2 de julho era a data comemorativa para a Confederação do Equador. ${ }^{12}$ 


\section{Considerações finais}

No Instituto Histórico e Geográfico Brasileiro, Pedro Lessa foi historiador ao demonstrar conhecer a historiografia e os conceitos modernos da História, por consultar as fontes frequentando bibliotecas e arquivos. Mas também foi juiz ao emitir pareceres, ao absolver Varnhagen das acusações que considerava injustas e ao interromper a disputa acerca de uma data comemorativa. Dito de outro modo, ao me apropriar da categoria autor de Foucault foi possível perceber que sob a assinatura de Lessa determinou-se quem era historiador no presente, quem foi historiador no passado e uma data histórica para o futuro. Assim, se por um lado, Lessa era um sócio sereno e justo, conforme necessidade do IHGB, por outro, ele exerceu a função do historiador togado. As necessidades da historiografia do período possibilitaram o surgimento de uma singularidade, o Juiz-Historiador, aquele que narra, julga, absolve e sentencia.

\section{Referências bibliográficas}

ACTAS DAS sessões realizadas no anno de 1912. Revista do Instituto Histórico

e Geográfico Brasileiro, tomo LXXV, parte II, p. 221-583, 1913.

ACTAS DE sessões de 1914. Revista do Instituto Histórico e Geográfico

Brasileiro, t. LXXVII, parte II, p. 497-653, 1916.

ACTAS DAS sessões de 1915. Revista do Instituto Histórico e Geográfico

Brasileiro, t. LXXVIII, parte II, p. 611-832, 1916. [Parecer de Pedro Lessa e o voto de Clóvis Beviláqua, p. 701-703].

ACTAS DAS sessões de 1916. Revista do Instituto Histórico e Geográfico

Brasileiro, t. 80, p. 611-868, 1917. [Conferência de Pedro Lessa em homenagem ao centenário de nascimento a Varnhagen, p. 613-666].

ACTAS DAS sessões de 1917. Revista do Instituto Histórico e Geográfico Brasileiro, t. 82, 1918, p. 764-769.

ANEXO: Documentos completos sobre a Confederação do Equador. Revista do Instituto Histórico e Geográfico Brasileiro, tomo 83, p. 351-426, 1918 (1919). [Laudo Definitivo de Pedro Lessa, p. 423-426].

AULETE, Caldas. Dicionário Contemporâneo da Língua Portugueza. Lisboa: Imprensa Nacional, 1881. v. 2.

DETONI, Piero. A síntese como desafio historiográfico na Primeira

República. Pequenos estudos de caso. Dissertação (Mestrado em História) - Universidade Federal de Ouro Preto, Mariana, 2013.

FIGUeIREDO, Candido de. Novo Dicionário da Língua Portuguesa. Lisboa: Tavares, Cardoso \& Irmão, 1899. v. 2. 
FOUCAULT, Michel. O que é um autor? Trad. Antônio Fernando Cascais e Eduardo Cordeiro. Lisboa: Nova Veja, 2006.

GOMES, Angela de Castro. A República, a história e o IHGB. Belo Horizonte, MG: Argvmentvm, 2009.

. História, ciência e historiadores na Primeira República. In: HEIZER, Alda. VIDEIRA, Antônio Augusto Passos (Org.). Ciências, civilizações e república nos trópicos. Rio de Janeiro: Mauad X, 2010, p. 11-29.

. História e Historiadores. Rio de Janeiro: Ed. Fundação Getúlio Vargas, 1996.

Pedro Lessa, Reflexões sobre o conceito da História. In: NICOLAZZI, Fernando (Org.). História e historiadores no Brasil: do fim do Império ao alvorecer da República (1870-1940). Porto Alegre: EDIPUCRS, 2015, p. $67-168$.

GUIMARÃES, Lúcia Maria Paschoal. Da Escola Platina ou Silogeu: Instituto Geográfico Brasileiro (1889-1938). Rio de Janeiro: Museu da República, 2007.

GUIMARÃES, Manuel Luiz Salgado. Historiografia e Nação Brasil (18381857). Rio de Janeiro: EdUERJ, 2011.

HRUBY, Hugo. Obreiros diligentes e zelosos auxiliando no preparo da grande obra: a História do Brasil no Instituto Histórico e Geográfico Brasileiro. (1889-1912). 2007. 233f. Dissertação (Mestrado em História) - Faculdade de Filosofia e Ciências Humanas, PUCRS, Porto Alegre, 2007.

ANHEZINI, Karina. Na entrecena da construção da história do Brasil (18781934). In: MEDEIROS, Bruno Franco et al. (Org.) Teoria e Historiografia: Debates Contemporâneos. Jundiaí: Paco, 2015, p. 233-246. v. 1.

LIMA. Ivana Stolze. Luís Maria da Silva pinto e o Dicionário da Língua Brasileira. Humanas, v. 28, n. 1, p. 33-67, 2006.

MALATIAN, Teresa. Oliveira Lima e a construção da nacionalidade. Bauru: EDUSC, 2001.

OLIVEIRA, Maria da Gloria. Crítica, Método e Escrita da História em João Capistrano de Abreu. Rio de Janeiro: Ed. FGV, 2013.

PINTO, Luiz Maria da Silva. Dicionário da Língua Brasileira. Ouro Preto: Tipographia de Silva, 1832.

RODRIGUES, Lêda Boechat. História do Supremo Tribunal Federal. 2. ed. Rio de Janeiro: Editora Civilização Brasileira S. A., 1991. v. II.

SESSÃO MAGNA comemorativa de $83^{\circ}$ aniversário de Instituto em 21 de outubro de 1921. Revista do Instituto Histórico e Geográfico Brasileiro, tomo 90, v. 144, p. 884, 1925 [discurso fúnebre de Ramiz Galvão, 21 out. 1921]. 
SESSÃO SOLENE especial em 2 de junho, comemorativa do Centenário da Confederação do Equador. Revista do Instituto Histórico e Geográfico Brasileiro, t. 96, v. 150, p. 372-418, 1927.

SILVA, Barbara Winther. A escrita da história no IHGB no final do Império e Primeira República. Dissertação (Mestrado em História) - Universidade Federal Rural do Rio de Janeiro, Seropédica, 2015.

VALENTE, Paulo Giovanni Gomes. Memórias da política, política da memória: o centenário da Confederação do Equador no Ceará (1924). Dissertação (Mestrado em História) - Universidade Federal do Ceará, Fortaleza, 2014.

VIEIRA, Domingos. Grande Dicionário Português ou Tesouro da Língua Portugueza. Porto: Typographia de Antônio José da Silva Teixeira, 1874. v. 5. 